\title{
ISOLAMENTO MECÂNICO DE FOLÍCULOS PRÉ-ANTRAIS DE CADELAS - EFEITO DO INTERVALO DE SECÇÃO
}

\author{
Kele Amaral Alves ${ }^{1}$, Benner Geraldo Alves ${ }^{1}$, Lívia Gobbi Arantes², Marcelo Emílio \\ Beletti², José Octavio Jacomini² \\ 1 UFG \\ 2 UFU \\ Correspondência: Kele Alves: kelevet@gmail.com
}

RESUMO: O propósito deste estudo foi avaliar a quantidade e a viabilidade de folículos pré-antrais isolados mecanicamente de ovários de cadelas em dois intervalos de secção diferentes. Ovários de fêmeas caninas $(n=10)$ foram seccionados com o aparelho tissue chopper em intervalos de 250 e $500 \mu \mathrm{m}$. Para quantificação folicular utilizou-se o microscópio invertido e para análise de viabilidade e qualidade, optou-se pelo microscópio invertido com fluorescência, associando os corantes fluorescentes Hoechst e iodeto de propídeo ao pool de folículos isolados. A média de folículos préantrais isolados nas espessuras testadas diferiu $(P<0,05)$ entre os intervalos de $250 \mu \mathrm{m}(25200)$ e $500 \mu \mathrm{m}$ (11000). A viabilidade e a qualidade medidas pela integridade da membrana basal, e presença de células da granulosa apresentaram melhores resultados junto aos folículos isolados na espessura de $500 \mu \mathrm{m}$, concluindo que este intervalo preserva melhor os folículos pré antrais isolados.

Palavras-chave: iodeto de propídeo; ovário; quantificação folicular

\section{MECHANICAL ISOLATION OF BITCH PREANTRAL FOLLICLES - EFFECT OF SECTION INTERVAL}

\begin{abstract}
The purpose of this study, was evaluate the quantity and viability of bitches preantral follicles mechanically isolated on two sectioning intervals. Canine ovaries $(n=10)$ were cut with a tissue chopper device, programmed to 250 and $500 \mu \mathrm{m}$. The inverted microscope was used for follicular quantifying, and for viability and quality analysis, was chosen the sweep laser microscope, associating fluorescent dyes, Hoechst and propidium iodide with the pool of isolated follicles. The average of isolated follicles was different $(P<0.05)$ between the tested thicknesses, $250 \mu \mathrm{m}(25200)$ and $500 \mu \mathrm{m}(11000)$. Viability and quality, measured by follicular membrane integrity and granulous cells presence, showed better results in the group of follicles isolated of $500 \mu \mathrm{m}$ thicknesses, concluding that this interval provides better preservation on preantral follicles.
\end{abstract}

Key Words: follicular quantifying; ovary; propidium iodide 


\section{INTRODUÇÃO}

As biotécnicas reprodutivas em pequenos animais têm sido pouco empregadas, sendo que um dos fatores limitantes em cães são a anatomia e a fisiologia peculiares desta espécie (Lopes, 2001). Diferente das demais espécies, pouco sucesso tem sido obtido com a transferência de embriões, bem como com a indução da superovulação em cadelas (Tsutsui et al., 1989).

O ovário mamífero contém milhares de ovócitos inclusos em folículos pré-antrais (FOPA). Entretanto, a grande maioria destes folículos $(99,9 \%)$ não chega até a ovulação, sendo eliminada por meio do processo de atresia folicular (Machado et al., 2002). A manipulação de ovócitos inclusos em folículos pré-antrais (MOIFOPA), possibilita o resgate e o isolamento de folículos pré-antrais (FOPA) a partir dos ovários, antes que eles se tornem atrésicos, permitindo seu cultivo e maturação (Figueiredo et al., 2002). Os FOPA são classificados em folículos primordiais, primários e secundários. Os primordiais são menores e possuem uma camada de células da granulosa de forma pavimentosa. Os folículos primários apresentam uma camada de células da granulosa de formato cubóide. Já os folículos secundários possuem mais de uma camada de células da granulosa com formato cubóide (Hulshof et al., 1994).

A manipulação in vitro de ovócitos recuperados da população de folículos ovarianos pré-antrais, além de servir de modelo nas investigações sobre os complexos mecanismos da foliculogênese inicial, tem um grande impacto na reprodução assistida de espécies em extinção e em animais de produção de alto valor genético. As possibilidades do emprego dos folículos ovarianos pré-antrais em sistemas de crescimento, maturação e fecundação in vitro abre um leque de novas alternativas para a seleção e melhoramento genético animal (Figueiredo et al., 1993; Telfer et al., 1999). Devido à proximidade filogenética dos cães com diversas espécies ameaçadas de extinção como o lobo Guará e o alto valor econômico de algumas raças raras, 0 aperfeiçoamento da biotécnica de MOIFOPA constitui uma importante ferramenta para a preservação destas espécies.

Para o isolamento de FOPA podem ser utilizados métodos mecânicos e/ou enzimáticos. O princípio dos métodos de isolamento folicular consiste na dissociação ou separação dos folículos pré-antrais dos demais componentes do estroma ovariano, utilizando-se para isto, instrumentos mecânicos associados ou não aos enzimáticos. Nos procedimentos mecânicos, os equipamentos mais comumente utilizados são o fatiador de tecidos (tissue chopper), míxers, tesouras cirúrgicas, pequenos fórceps e agulhas dissecantes. Já nos processos enzimáticos, as enzimas proteolíticas mais utilizadas são a colagenase, tripsina e pronase. Os métodos mecânicos oferecem menor risco de danos à estrutura folicular, sendo mais econômicos, rápidos e de maior facilidade de execução (Domingues et al., 2003). Todavia, não existem dados de literatura avaliando a melhor espessura das fatias de ovário para o isolamento de folículos pré-antrais em cadelas.

Objetivou-se com este estudo quantificar e avaliar a viabilidade de folículos pré-antrais de cadelas, isolados após procedimento mecânico no aparelho fatiador de tecidos, utilizando dois intervalos seccionais diferentes. 


\section{MATERIAL E MÉTODOS}

Foram utilizados 10 ovários de cadelas, entre 24 e 60 meses, sem raça definida, obtidos por meio de procedimento cirúrgico de ovariohisterectomia, realizados no Hospital Veterinário - UFU e em clínicas veterinárias no município de Uberlândia - MG, seguindo padrões de ética cirúrgica e anestésica.

Após a coleta, os ovários foram lavados com álcool $70^{\circ}$, acondicionados em frascos com solução tampão fosfatada (PBS) resfriada a $4^{\circ} \mathrm{C}$ e conduzidos ao laboratório dentro de uma caixa de isopor no período máximo de duas horas.

No procedimento de isolamento mecânico utilizou-se 0 aparelho fatiador de tecidos calibrado para espessuras de corte de $250 \mu \mathrm{m}$ e $500 \mu \mathrm{m}$, distribuindo aleatoriamente 5 ovários de diferentes cadelas para cada tratamento. Para uma fragmentação mais eficiente, os ovários foram umedecidos no cortador de tecidos com solução de PBS e os cortes foram realizados nos sentidos longitudinal e transversal. Os fragmentos ovarianos obtidos foram colocados em solução de $5 \mathrm{~mL}$ de PBS e dissociados mecanicamente por repetidos movimentos de sucção e ejeção utilizando-se, sucessivamente, pipetas de Pasteur calibradas a 1600 $\mu \mathrm{m}$ (20 movimentos) e $600 \mu \mathrm{m}(20$ movimentos) de diâmetro. A suspensão obtida foi filtrada, primeiramente, em malha de náilon de $500 \mu \mathrm{m}$ e, posteriormente, de $100 \mu \mathrm{m}$ de diâmetro, com a finalidade de separar os FOPA dos fragmentos de tecido ovariano com dimensões maiores que $100 \mu \mathrm{m}$ de diâmetro, procedimento adaptado de Rodrigues et al. (1998).

Para estimar a quantidade de FOPA isolados utilizou-se a metodologia adaptada de Figueiredo et al. (1993). O filtrado resultante $(5 \mathrm{~mL})$ foi cuidadosamente agitado para a dispersão dos folículos. Em seguida, colocou-se em placa de Petri, uma amostra de $50 \mu \mathrm{L}$ do pool processado, sob microscópio invertido para a contagem dos folículos isolados, em aumento de 120 vezes. O número de folículos pré-antrais observados foi multiplicado por 20 para adequar os valores de microlitros para mililitros e, posteriormente, pelo volume final (5 $\mathrm{mL}$ ), estimando a quantidade total de folículos para cada ovário.

A avaliação quanto à presença de células da granulosa foi realizada em microscópio invertido de fluorescência, utilizando $1 \mu \mathrm{L}$ do corante fluorescente Hoechst 33342 em $1000 \quad \mu \mathrm{L}$ (concentração final de $10 \mu \mathrm{g} / \mathrm{mL}$ ) do pool de folículos isolados. Para avaliar a viabilidade folicular, também no mesmo aparelho, utilizou-se $50 \mu \mathrm{L}$ do corante fluorescente iodeto de propídeo em 50 $\mu \mathrm{L}$ (concentração final de $10 \mu \mathrm{g} / \mathrm{mL}$ ) do pool folicular. Ambas as amostras ficaram 30 minutos em estufa a $37^{\circ} \mathrm{C}$ ao abrigo da luz, fornecendo uma alíquota de $70 \mu \mathrm{L}$ cada para análise entre lâmina e lamínula.

A análise estatística foi realizada utilizando um software específico e os valores expressados como média e erro padrão. Os dados da quantificação folicular e do número de células da granulosa presente de acordo com os intervalos de corte testados foram analisados pelo teste de Kruskal-Wallis. A viabilidade e a classificação folicular foram analisadas pelo teste Quiquadrado. Os resultados foram considerados significantes quando $\mathrm{P}<0,05$.

\section{RESULTADOS E DISCUSSÃO}

Ambos os intervalos de corte proveram uma quantidade satisfatória de FOPA isolados por ovário, no entanto foram recuperadas mais estruturas $(P<0,05)$ quando utilizado o corte de 
$250 \mu \mathrm{m}(25200 \pm 6676)$ em relação ao de $500 \mu \mathrm{m}(11000 \pm 2727)$. Uma alta variação individual de folículos foi observada nos dois intervalos de corte, com valores oscilando entre 7700 e 42000 (Tabela 1). Vários estudos em diferentes espécies (suíno: Greenwald e Moor, 1989 e Alves, 2010; canino: Durrant et al., 1998; felinos: Jewgenow, 1996; caprinos: Rodrigues et al., 1998) reportaram grandes variações na quantidade de folículos isolados por ovário, independente do tipo de procedimento adotado (enzimático ou mecânico).

Tabela 1 - Número de folículos pré-antrais recuperados de ovários de cadelas de
acordo com o intervalo de corte utilizado. Média e erro padrão.

Letras diferentes na mesma coluna diferem significativamente. $P<0,05$.

Essas diferenças podem estar relacionadas com idade, peso ovariano e fase reprodutiva. Em cadelas, Durrant et al. (1998) não encontraram essa associação com peso ovariano e fase reprodutiva, no entanto isolaram menos folículos de fêmeas jovens ( $\leq 6$ meses) em comparação as de meia idade (entre 7 e 48 meses).

Domingues et al. (2003) isolaram mecanicamente folículos pré-antrais de ovários de primatas (Cebus apella), testando espessuras de corte de 250 , 500, 750 e $1000 \mu \mathrm{m}$ e reportaram que o número de FOPA obtidos no corte de $500 \mu \mathrm{m}$ (300830) foi estatisticamente superior aos demais. Estudo com ovários bovinos seccionados mecanicamente em oito espessuras de corte $(25,50,75,100,125,150,175$ e $200 \mu \mathrm{m})$ demonstrou que com 0 intervalo de $125 \mu \mathrm{m}$ obteve-se o maior número (25632) de folículos isolados (Lucci et al., 2002). Em ovinos, Amorim et al. (2000) evidenciaram a influência da espessura de corte no total de folículos isolados por ovário, onde a melhor taxa de recuperação foi observada na secção de $87,5 \mu \mathrm{m}$ (6368).

Para melhor identificação dos FOPA isolados, utilizou-se o corante Hoechst 33342 que por corar componentes nucleares, permite a visualização individual de células da granulosa além da determinação de seu número e forma (Figura 1). No presente estudo o intervalo de $500 \mu \mathrm{m}$ proporcionou uma porcentagem maior $(P<0,05)$ de folículos cobertos com células da granulosa e maior número $(P<0,05)$ destas estruturas por folículo isolado quando comparado ao intervalo de $250 \mu \mathrm{m}$ (Tabela 2). Estes dados indicam que o maior intervalo de corte preserva melhor a morfologia dos folículos pré-antrais, resultando em melhor qualidade dos mesmos.

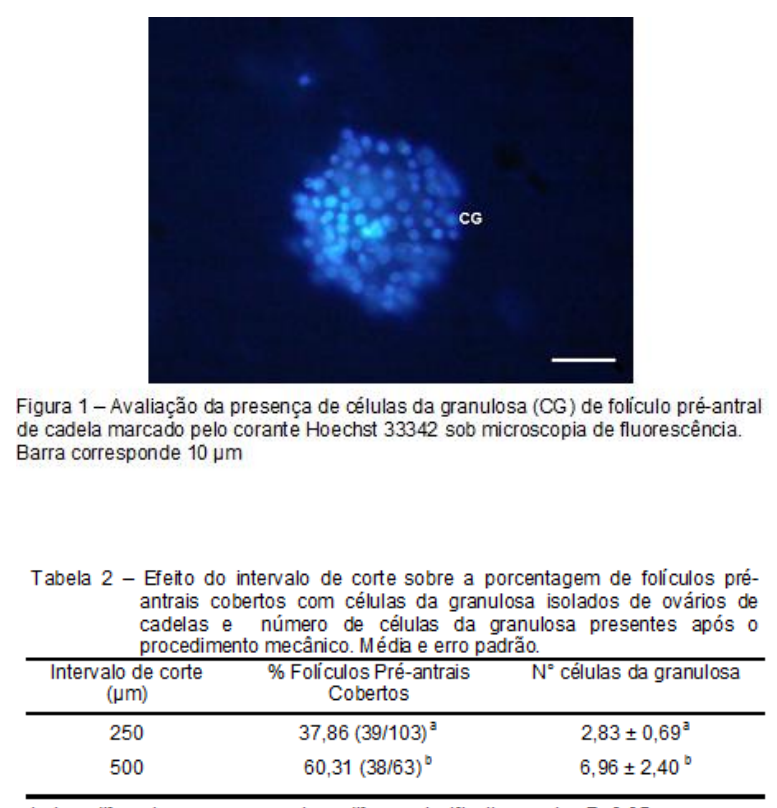

Letras diferentes na mesma coluna diferem significativamente. $P<0,05$.

Alguns pesquisadores (Nayudu et al., 1992; Jewgenow, 1998) observaram que folículos que conservam sua estrutura apresentam uma ou mais camadas de células da granulosa circundantes ao ovócito e aderidas à membrana basal. A presença da membrana basal em folículos isolados pode afetar a eficiência do cultivo in vitro 
oferecendo uma série de vantagens, como a preservação da morfologia celular e manutenção da adesão aos componentes extracelulares (Figueiredo et al., 1994; Machado et al., 2002). Vários corantes como o azul de trypan, calceína-AM e etídio homodímero podem ser associados ao corante Hoechst 33342 para testar a viabilidade, número de células da granulosa e integridade de folículos pré-antrais caninos em diferentes meios de preservação (Lopes et al., 2009).

As células da granulosa são indispensáveis para o crescimento do ovócito, diferenciação, divisão nuclear, maturação citoplasmática e atividade transcripcional genômica (Van Den Hurk, 2005). Estas células estão ligadas entre si e com o ovócito através de junções do tipo gap nas zonas de transposição citoplasmática, onde ocorre comunicação bidirecional, permitindo a troca de nutrientes, precursores metabólicos (aminoácidos e nucleotídeos), moléculas informacionais (hormônios, neurotropinas e fatores de crescimento) e sinais estimulatórios e inibitórios da meiose. Assim, o ovócito pode promover ativamente 0 crescimento e a diferenciação das células foliculares, do mesmo modo que as células da granulosa estimulam 0 crescimento e a diferenciação do ovócito (Anderson e Albertini, 1976).

As células foliculares e o ovócito possuem um sistema de transporte ativo, gerando um gradiente eletroquímico que é fundamental para o perfeito funcionamento celular. Quando esse sistema falha (morte celular) ocorre a despolarização da membrana citoplasmática e sua conseqüente permeabilização. O corante fluorescente iodeto de propídeo foi o escolhido para testar a viabilidade dos folículos isolados, devido ao fato de não atravessar as membranas citoplasmáticas polarizadas, corando então, apenas as células mortas de vermelho (Silva et al., 2001).

Os resultados obtidos (Tabela 3) apontaram diferenças significantes na viabilidade dos FOPA, entre os intervalos de corte adotados para 0 isolamento. Entretanto, a avaliação preditiva em função do número de folículos viáveis e isolados por ovário demonstrou que ambas as secções propiciaram a recuperação de milhares de folículos. Alves (2010) utilizou iodeto de propídeo no pool de estruturas foliculares isoladas mecanicamente de ovários suínos e constatou taxa de viabilidade de $76 \%$, próxima à encontrada no intervalo de $500 \mu \mathrm{m}$ deste trabalho.

Lopes et al. (2009) reportaram resultados semelhantes de taxa de viabilidade (79 a 83\%) em cadelas, após 0 isolamento de FOPA no tissue chopper, utilizando intervalo de corte de 87,5 $\mu \mathrm{m}$. Em felinos não domésticos, Jewgenow et al. (1996), observaram taxas de integridade de membrana dos folículos pré-antrais, isolados mecanicamente, entre 20 e 50\%. Machado et al. (2002) avaliando a viabilidade de folículos pré-antrais de fetos caprinos, isolados pelos métodos enzimático e mecânico, concluíram que ambos os procedimentos podem ser usados com a mesma eficiência, apesar do método enzimático apresentar maior porcentagem de FOPA viáveis (84\% versus $75 \%$ ).

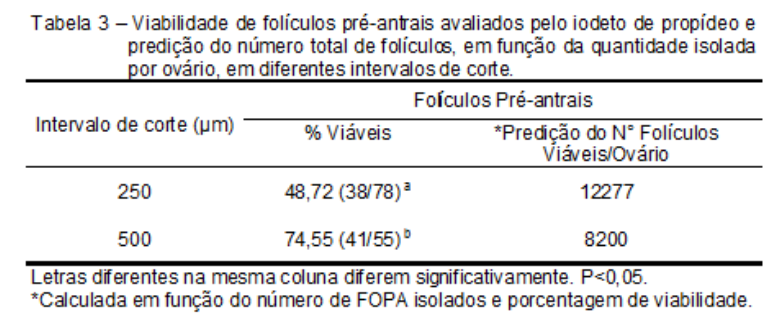




\section{CONCLUSÃO}

O isolamento mecânico mostrouse eficiente em ambos os intervalos de corte quanto à quantidade de folículos pré-antrais viáveis isolados, no entanto o intervalo de $500 \mu \mathrm{m}$ preservou melhor a morfologia das estruturas foliculares, sendo tais parâmetros essenciais para posterior cultivo in vitro.

\section{AGRADECIMENTO}

A Fundação de Amparo à Pesquisa do Estado de Minas Gerais FAPEMIG.

\section{REFERÊNCIAS}

\section{ALVES, B.G. Isolamento, quantificação e classificação de folículos pré-antrais de suínos. 2010. Uberlândia, 53f. Dissertação (Mestrado em Ciências Veterinárias) - Curso de Pós-graduação em Ciências Veterinárias, Universidade Federal de Uberlândia.}

ANDERSON, E.; ALBERTINI, D.F. Gap junctions between oocyte and companion follicle cells in the mammalian ovary. Journal of Cellular Biology, v.71, p.680-686, 1976.

AMORIM, C.A.; RODRIGUES, A.P.R.; LUCCI, C.M. et al. Effect of sectioning on the number of isolated ovine preantral follicles. Small

Ruminant Research, v.37, n.3, p.269-277, 2000.

DOMINGUES, S.F.S.; FERREIRA, H.S.; MUNIZ, J.A.P.C. et al. Mechanical isolation of capuchin monkey (Cebus apella) preantral ovarian follicles. Arquivo Brasileiro de Medicina Veterinária e Zootecnia, v. 55, n. 3, p.301-308, 2003.

DURRANT, B.S.; PRATT, N.C.; RUSS, K.D. et al. Isolation and characterization of canine advanced preantral and early antral follicles. Theriogenology, v.49, n. 5, p.917-932, 1998.

FIGUEIREDO, J.R.; HULSHOF, S.C.J.; VAN DEN HURK, R. et al. Development of a combined new mechanical and enzymatic method for the isolation of intact preantral follicles from fetal, calf and adult bovine ovaries. Theriogenology, v.40,n.4, p.789-799, 1993.

FIGUEIREDO, J.R.; HULSHOF, S.C.J.; VAN DEN HURK, R. et al. Preservation of oocyte and granulosa cell morphology in bovine preantral follicles cultured in vitro. Theriogenology, v.41, n.6, p.1333-1346, 1994

FIGUEIREDO, J.R.; RODRIGUES, A.P.R.; AMORIM, C.A. Manipulação de Oócitos Inclusos em Folículos Ovarianos Pré-antrais - MOIFOPA. In: GONÇALVES, P.B.D.; FIGUEIREDO, J.R.; FREITAS, V.J.F. Biotécnicas Aplicadas à Reprodução Animal. 1.ed. São Paulo: Editora Varela, 2002. p.227-260.

GREENWALD, G.S.; MOOR, R.M. Isolation and preliminary characterization of pig primordial follicles. Journal of Reproduction and Fertility, v.87, p.561-571, 1989.

HULSHOF, S.C.J.; FIGUEIREDO, J.R.; BECKERS, J.F. et al. Isolation and characterization of preantral follicles from foetal bovine ovaries. Veterinary Quarterly, v.16, n.2, p.78-80, 1994.

JEWGENOW, K.; STOLTE, M. Isolation of preantral follicles from nondomestic cats-viability and ultrastructural investigations. Animal Reproduction Science, v.44, n.3, p.183-193, 1996.

JEWGENOW, K. Role of media, protein and energy supplements on maintenance of morphology and DNA-Synthesis of small preantral domestic cat follicle during short-term culture. Theriogenology, v.49, n.8, p.15671577, 1998.

LOPES, M.D. Técnicas de reprodução assistida em pequenos animais. Revista de Educação Contínua CRMV-SP, v.4, n.1, p.33-39, 2001.

LOPES, C.A.P.; SANTOS, R.R.; CELESTINO, J.J.H. et al. Short-term preservation of canine preantral follicles: Effects of temperature, médium and time. Animal Reproduction Science, v.115, n.1-4, p.201-214, 2009.

LUCCI, C.M.; RUMPF, R.; FIGUEIREDO, J.R. et al. Zebu (Bos indicus) ovarian preantral follicles: morphological characterization and development of and efficient isolation method.

Theriogenology, v.57, n.5, p.1467-1483, 2002.

MACHADO, V.P.; RODRIGUES, A.P.R.;

BRASIL, A.F. et al. Isolamento mecânico e enzimático de folículos ovarianos pré-antrais de fetos caprinos. Ciência Animal, v.12, n.2, p.8391, 2002.

NAYUDU, P.L.; OSBORNE, O.S. Factors influencing the rate of preantral and antral growth of mouse ovarian follicles in vitro. Journal of Reproduction and Fertility, v.95, p.349-362, 1992. 
RODRIGUES, A.P.R.; AMORIM, C.A.; LUCCI, C.M. et al. Isolamento mecânico de folículos ovarianos pré-antrais em cabras. Ciência Rural, v.28, n.3, p.477-482, 1998.

SILVA, T.L.; REIS, A.; HEWITT, C. Citometria de fluxo: funcionalidade celular on-line em bioprocessos. Biology Biotecnology, p.32-40, 2001.

TELFER, E.E.; WEBB, R.; MOOR, R.M. New approaches to increasing oocyte yield from ruminants. Animal Science, v.68, n.2, p.285298, 1999.

TSUTSUI, T.; SHIMADA, K.; NISHI, M. et al. An experimental trial on embryo transfer in the dog. Japanese Journal of Veterinary Science, v.51, n.4, p.797-800, 1989.

VAN DEN HURK, R.; ZHAO, J. Formation of mammalian oocytes and their growth, differentiation and maturation within ovarian follicles. Theriogenology, v.63, n.6, p.17171751, 2005. 